\title{
The Study on Design Thought of Delicacy Management System forCollege Students Based on Big Data Idea
}

\author{
Yang Zhao ${ }^{1, \mathrm{a}}$,Ningning Zheng ${ }^{1}$ \\ ${ }^{1}$ Shandong Agriculture and Engineering University, Jinan 250100,China. \\ azay@163.com
}

Keywords: Big data, student management, delicacy management system.

\begin{abstract}
With the development of technology, a simple data analysis can't satisfy daily management needs of enterprises and organizations any more. The advent of big data technique brings in an enormous innovation on the traditional analysis mode of data management. The paper conducts a brief analysis on basic conception, treatment scheme and related techniques of big data, applies big data idea to design delicacy management system for college students, and from the perspective of theory, proposes design thought that conforms to big data idea from technological base of the system, ways of data sources, data integration process, analysis model design and key problems of system design, etc.
\end{abstract}

\section{Introduction}

At present, domestic colleges and universities have already utilized various student management systems to conduct informatization management on study and life for college students. However, the design of current student management systems utilized in universities is mainly based on the traditional information management system (IMS). The management system based on IMS idea mainly conducts a management analysis on formative original data that is collected in quantification. Data sources of the system are single. Analysis techniques and means are formative. Because classification of managed objects is simple and fixed, and management of individual differences is undefined, it can't refine, individualize and conduct single object management. Analysis results of the management system that is based on IMS idea impact less veracity and reliability on student management gradually. With the development of technology and advent of the big data era, all industries can profit from applications of big data, such as enterprise statistical data, medical data, Internet data and mobile data, etc[1, 2]. Meanwhile, the big data technique also offers a new development direction to design the delicacy management system for college students.

\section{The Big Data Theory and Techniques}

Gartner, which is a famous research institute, defines that big data requires for a new processing mode to possess stronger decision-making power, insight, process optimization in quantity, high rate of growth and diversified information assets. Mckinsey\& Company defines the big data as a data set, which can't collect, store, manage and analyze its contents within a certain time by applying traditional database software tools. Though, definitions of big data are not the same, the industry generally thinks that the big data has characteristics of $4 \mathrm{~V}$, namely Volume, Variety, Velocity and Value [3].

The idea of big data technique regards a new data processing technique as a method to analyze inherent regularities and value embodiment of mass data rapidly, which are in quantity and have heterogeneity and diversified contents, so as to conduct quantitative judgment and trend prediction on objects that are analyzed. Generally speaking, big data processing flow can be divided into several stages of data acquisition, data integration, analysis and explanation of data [4].

In the data acquisition, sources of big data aren't restricted to only collect quantitative data and make database design model any longer. Related data of objects that are analyzed has already translated into real-time collection of mass data generated deliberately or unwittingly by objects that 
are analyzed from man-made and conscious activities. Furthermore, generally speaking, data-gathering process is conducted under the unknowing circumstance of objects that are analyzed. Data-gathering process is filled with applying "Internet of Things" and "cloud computing”, etc. various new techniques, such as sensor acquisition, RFID acquisition, access to webpage clicks and access to application services in mobile devices, etc.

Data integration mainly completes extraction, cleaning and storage of received data ${ }^{[4]}$. It can be known from definitions of big data that received data may have multiple structures and types. Extraction is to translate complicated data into the data structure that is convenient for processing with the purpose of achieving rapid analysis and process. Data cleaning: Not all data in an extractive mass data set are equipped with break-up value. In other words, some data may not analyze contents in demand, while other data may be totally wrong disturbance terms. How to extract valid data in a mass data set is a main duty of data cleaning. One of methods is to design all kinds of filters, which can prevent "disturbed" data from impacting accuracy of the analysis by filtering out useless and wrong data with rules. Data storage stores valid data that is processed preliminarily. If these records are only put in one or multiple storage cells at random, instead of taking conveniences of access into consideration, it may cause that the data is difficult to reuse. Therefore, designing suitable data storage can improve conveniences of data access effectively.

Data analysis: When users propose system access request, big data system needs to conduct reasonable modeling analysis and feedback analysis results in accessible form to users. User demands are multitudinous. Thus, it asks to design analytical methods, analysis model species and ways of result feedback complicatedly and variously for the big data processing system.

\section{Wisdom Campus}

Utilization of the big data technique can't be separated from acquisition of abundant and diversified data. For delicacy management system for college students based on the big data idea, how to acquire various data related to student management becomes the basic issue of systematic design. Students are objects of analysis system management. It is not difficult to find that main living environment of students primarily involves in the campus. The "data" collected in the big data idea is various data produced by daily activities of process objects. From the perspective of students, generation of daily data mainly concentrates on the scope of the school. The establishment of "wisdom campus" provides reliable data support for data sources of college students' delicacy management system.

With the advent of cloud computing and Internet of Things, the campus information construction goal also has a new change----production of "wisdom campus". Various research data at home and abroad, there are many descriptions on involved contents of "wisdom campus". Two descriptions that relate to research contents of this paper directly are selected: first, based on Internet of Things and regarding various application service systems as carriers, the new-type wisdom working, learning and living environment that integrates with teaching, scientific research, management and campus life is constructed. By utilizing advanced information technological means, the application system based on digital environment is realized [5]. Second, first of all, internet environment is ubiquitous and convenient; then, owning a data environment is the computing environment and storage environment; next, a system (Internet of Things system) connection supports for the environment of various intelligent terminal, facilities and equipment networking[6,7].

It can be observed from descriptions of "wisdom" combining with big data idea that "wisdom" in the "wisdom campus" mainly reflects in the establishment of data environment. Campus data collects through Internet of Things and provides services based on data foundation through various application systems. In hardware environment, "wisdom campus" conducts networking with all kinds of intelligent terminals, facilities and equipment, which can gather daily data generated at anytime. Various data generated in "wisdom campus" are interlinked with daily data in big data idea. All types, structures and contents in various data are different. Meanwhile, enormous data size can be integrated and processed as big data processing system of essential data. The number of students at colleges and universities is far more than the number of teachers. Therefore, subjects of data 
generated in corresponding "wisdom campus" are students. Moreover, service areas of "wisdom campus" are within the university campus and contain the main ranges of activities for subjects: students. The data generated by subjects within ranges has stronger reliability, higher concentration ratio and excellent distributivity within the range, so as to better embody daily activities of subjects: students.

In conclusion, management subjects researched in delicacy management system for college students of this paper are students. Management subjects in "wisdom campus" generate heterogeneity, diversification and mass data. Furthermore, data can indicate the essence of subjects. Therefore, "wisdom campus" can offer an excellent data foundation on realizing design of student management system based on big data idea.

\section{The Systematic Design Thought}

Data Integration.Data collection is a premise and basic link of data processing. If there is no data collection, there are no objects of data processing, let alone data processing. The core idea of management system researched in this paper is the big data idea. As a result, which data should be collected by this system becomes the primary task of systematic design. Of course, under the background of big data idea, the data is associated and integrated. Moreover, it associates and integrates various data that relate to analysis objects.

From the perspective of society, student activities exist in the social large system. In view of original sensibility of some data and difficulty of collection, such as, bank data, medical data and data of individual privacy, etc., these data are impossible to be acquired by the mini system of the school. Thus, we should shrink the big data idea. The scope of acquiring data should decrease to the range of mini system----the school. Combining with above-mentioned descriptions of "wisdom campus", the data of students generated in campus activities also is the main data of student objects. Moreover, the data within the campus range even more reflect the practice of student activities directly. These data are also within the controllable and collectable range of the school simultaneously. At present, domestic college management contents are inundated with various management systems, such as student performance management system, campus card management system and books management system, etc. Students live in the campus, so mass data will be generated at anytime, such as performance data, campus Internet records, campus card consumption records, and library borrowing records, etc. Dealing with these recorded data separately can only reflect students' performance in certain management space. Provided that various management data are associated and integrated in line with a certain rule (model), it can reflect students' track in campus life really.

Design Thought of the Analysis Model.Student management at colleges and universities is all-around. Therefore, the data generated in student schedules also is all-around. In the design thought of delicacy student management system, the author thinks that these data can be divided into two categories: life data and learning data.

(1) Life data: these data are primarily generated by school life of students, such as One-Card consumption data, data of electricity utilization and water requirements and communication consumption data, etc. Student life data can reflect students' capital position directly and indicate detail degree of student life management provided by the school indirectly. When conducting student life management, the systematic analysis model should give priority to these data for modeling.

Based on evaluating financial assistance of poverty students, financial assistance of poverty students should mainly aid those students who have lower household incomes, cant' assume tuition and living expenses. Nowadays, generally speaking, the method adopted by the school is to apply by students themselves. Moreover, they provide individual situation of household incomes, while the school is responsible for examining and verifying. Approval of the school mainly depends on the people who are audited. For data provided by people who are audited, the school is impossible to implement completely. Therefore, results of approval have a certain error. From another 
perspective, if the school audits students' consumption situation at school, results will be clear at a glance. Generally speaking, poverty students may not have higher consumption. Therefore, in the analysis model of auditing financial assistance of poverty students can apply the following data to analyze.

(1) One-Card consumption data: One-Card consumption data is a main consumption method of students at school. From recharge to consumption, the school can conduct a whole-process monitor. Statistics of students' One-Card consumption situation can show students' main conditions of consumption at school directly, from the number of recharge amount to sum of consumption of every meal, it can record. The data can be listed in the analysis model as major reference frame.

(2)Communication consumption data: students' mobile phone communication within the campus can be recorded through wireless network base station. First, this record can indicate students' conditions of communication consumption at campus. Second, it also can show students' lingering duration at school, reflecting students' time of after-school activities indirectly.

(3)Library borrowing data: the data can reflect time and lingering duration when students are in and out the library, reflecting main site of students' campus activities directly.

(4)Webpage access data: generally speaking, the school has free network access to students. It often regards student number as the account number to login. Through techniques, students' consumption conditions of website access and shopping online, etc. can be acquired.

To sum up, if a student is a poverty student, his consumption certainly will be lower. Moreover, if he spends his spare time on the library and reading room, etc. non-consuming places, it can firmly believe that poverty of this student is the case. It can identify his application qualification of student subsidies. Of course, the above-mentioned analysis is just a theoretical model. In practical design, reference coefficient proportion of every data can be set. The responsive end value can be calculated through proportional formula. Responsive qualification can be confirmed by ranking.

(2) Learning data: the data is generated in students' school learning, such as school attendance, examination performance data, course selection data and library borrowing data, etc. The data indicates the learning situation of students at school and learning results. In management, these data can be used for an important analysis foundation of evaluating student scholarships, cultivating learning interests and formulating individual learning plans, etc. management contents. Corresponding analysis model design is the same with the design thought of the assessment model of financial assistance of poverty students. Both of them can be drawn by integrating proportion analysis of various data. It won't be explained here.

Key Problems of Systematic Design.Design idea of delicacy management system for students is based on big data analysis and is different from regular MIS systematic design. This system should adopt more big data technologies to design from data modeling to systematic detailed design. In technologies, it should solve the following key problems.

(1) Multi-source data integration and processing design: there are many sources for the above-mentioned data, such as financial data, performance data and library data, etc. These different data root in different management systems, so when integrating, it definitely will involve in differences of different data types, diverse data structures and disparate data storage modes. The feasible method is to adopt the big data technology. First, extract data from the multi-source database to integrated database buffer, and then, extract and clean data, finally, store useful data in the available database. When users access to it, they can select data from the data analysis server to available data database, conduct the model analysis on the existing model through an analysis server, return analysis results to users, preserve in the result data database simultaneously, so as to be convenient for examining at anytime. Integration and treating processes of systematic data are shown in Figure 1. 


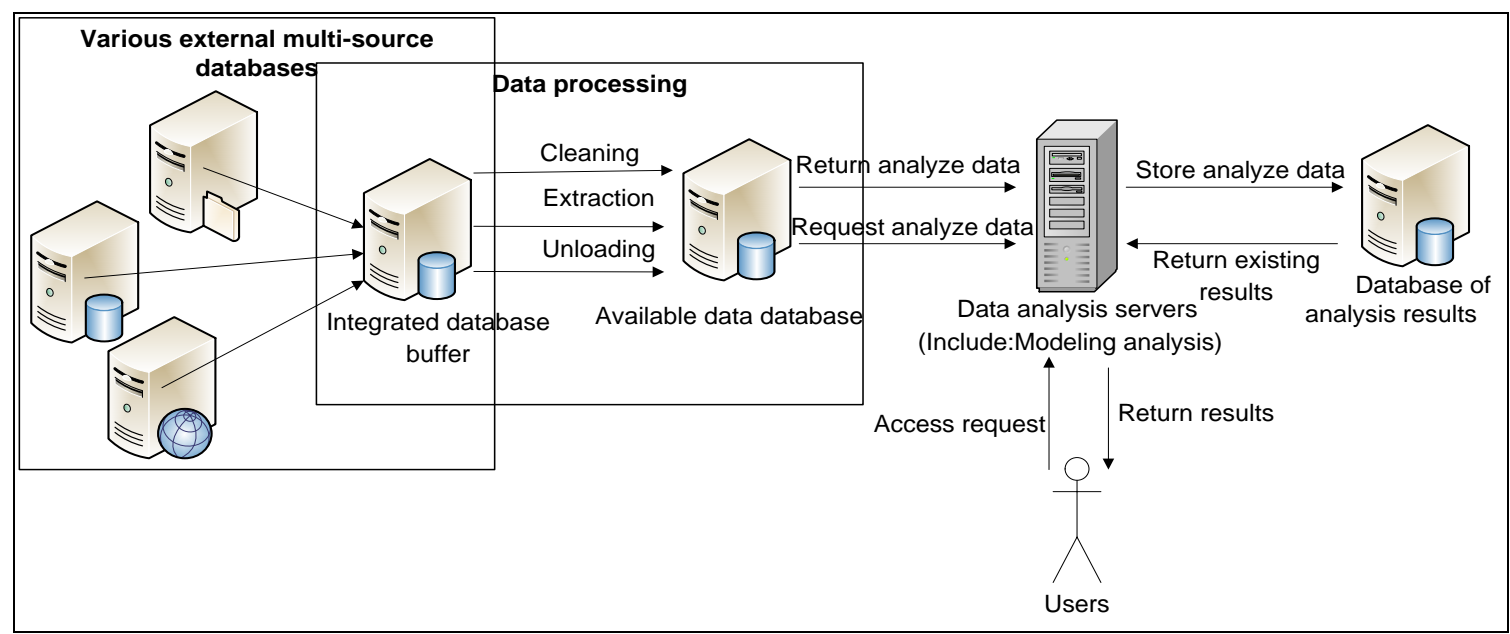

Figure 1. Treatment Design of Systematic Data [4]

(2) Analysis model design: in the process of conducting delicacy management for students, in order to make data analysis results more persuasive, it should utilize the big data analysis method. For example, by combining with statistical data and machine learning, we can use the database management technology to extract useful information and knowledge-based technologies from large-scale data concentration. According to its property values, we can predict property values of specific (targets), such as regression, classification and anomaly detection, etc. Or we can look for modes that have potential relations in general data, such as association analysis, evolutionary analysis, cluster analysis, sequence pattern excavation, etc[8].

(3) Systematic architecture design: systematic overall architecture design should adopt popular $\mathrm{B} / \mathrm{S}$ framework to design, and make analysis and processing service enclose the data analysis server and data processing server. The user side will present analysis results directly and make analysis procedure become transparency to users. In addition, utilization of this framework can make users apply this system at anytime and anywhere.

\section{Conclusions}

The big data era has already arrived. Reasonable utilization of the big data technology also opens up a new development direction in traditional data management analysis field. Application of the big data idea in delicacy management system design for college students is a kind of exploratory research on a specific application of the big data technology. Nowadays, with the constant popularization and development of Internet of Things and network techniques at colleges, the "wisdom campus" provides a favorable campus data foundation for collecting system data. Comparing with social data and enterprise data, campus data may not reach the requirement of big data in the mass and width. However, the application of big data idea has no limitation. No matter which kind of technology, as long as it can reach the requirement of system objectives, its utilization will be reasonable. Systematic design thought proposed in this paper offers corresponding design reference to future systematic detailed design and similar system design. With an improvement upon technology, utilization of big data idea in management will be increasingly increased.

\section{References}

[1] Informatica. Big data unleased. 2011. http://www.informatica.com/downloads/1601_big_data_wp.pdf

[2] $\mathrm{S} \mathrm{Ma}, \mathrm{JX} \mathrm{Li}, \mathrm{CM} \mathrm{Hu}$. The challenge and thinking of big data science and engineering. Communications of the China Computer Federation, 2012,8(9):22-28. (In Chinese)

[3] BARWICK H. The “fourVs" of big data.Implementing Information Infrastructure ymposium [EB/OL]. [2012-10-02]. http://www.computerworld.com .au/article/396198/iiis_four_vs_big_data/. 
[4] W C Dou, C Jiang, Big Data: Technical Ecosystem and Problem Discovery [J] ZTE Communications, 2013, 19(4):8-16. (In Chinese)

[5] P H Zhou,Informationalized Level Assessment and Development Prediction Research on Higher Education in Our Country [D], Wuhan: Central China Normal University, 2012. (In Chinese)

[6] Z Y Gu, The Empirical Research on Academic Performance's Influence Factors of Young University Teachers----Based on the Variation Analysis between Personality Characteristics and Organizational Factors [J], Higher Education Exploration, 2011, (1): 129-136. (In Chinese)

[7] C H Yu, Y W Wang, Goals, Contents and Strategies of Digital Campus Construction under Big Data Background [J], Chinese Educational Technology, 2013,(10):30-35. (In Chinese)

[8] X F Yan, D X Zhang, Big Data Research [J], Computer Technology and Development, 2013, 23(4): 168-172. (In Chinese) 